\title{
A Novel Miniature CRISPR-Cas13 System for SARS-CoV-2 Diagnostics
}

\author{
Ahmed Mahas, Qiaochu Wang, Tin Marsic, and Magdy M. Mahfouz* \\ Cite This: https://doi.org/10.1021/acssynbio.1c00181 \\ Read Online
}

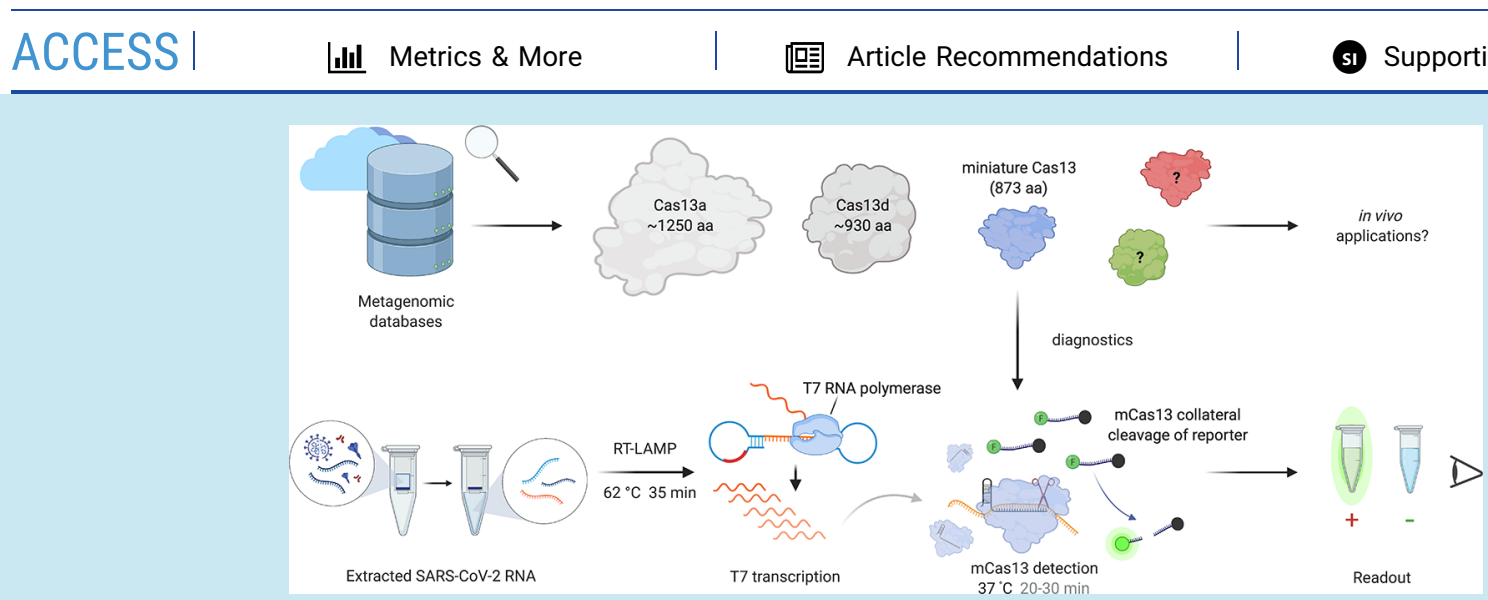

ABSTRACT: Rapid, point-of-care (POC) diagnostics are essential to mitigate the impacts of current (and future) epidemics; however, current methods for detecting severe acute respiratory syndrome coronavirus 2 (SARS-CoV-2) require complicated laboratory tests that are generally conducted off-site and require substantial time. CRISPR-Cas systems have been harnessed to develop sensitive and specific platforms for nucleic acid detection. These detection platforms take advantage of CRISPR enzymes' RNA-guided specificity for RNA and DNA targets and collateral trans activities on single-stranded RNA and DNA reporters. Microbial genomes possess an extensive range of CRISPR enzymes with different specificities and levels of collateral activity; identifying new enzymes may improve CRISPR-based diagnostics. Here, we identified a new Cas 13 variant, which we named as miniature Cas 13 (mCas13), and characterized its catalytic activity. We then employed this system to design, build, and test a SARSCoV-2 detection module coupling reverse transcription loop-mediated isothermal amplification (RT-LAMP) with the mCas13 system to detect SARS-CoV-2 in synthetic and clinical samples. Our system exhibits sensitivity and specificity comparable to other CRISPR systems. This work expands the repertoire and application of Cas 13 enzymes in diagnostics and for potential in vivo applications, including RNA knockdown and editing. Importantly, our system can be potentially adapted and used in large-scale testing for diverse pathogens, including RNA and DNA viruses, and bacteria.

KEYWORDS: Cas13, COVID-19, SARS-CoV-2, RT-LAMP, biosensors, point-of-care diagnostics

\section{INTRODUCTION}

At-home or point-of-care (POC) diagnostics are essential for effectively managing pathogen outbreaks and pandemics, including COVID-19. ${ }^{1}$ POC testing can accurately and rapidly identify and isolate symptomatic and asymptomatic carriers and thereby contribute to limiting virus spread and protecting vulnerable individuals at risk due to pre-existing conditions. ${ }^{2}$ Low-cost, frequent, and fast-turnaround testing is critical to curbing virus spread. POC testing has quick turnaround times and is efficiently deployed in low-resource areas and pop-up centers; is easy to use and does not require highly trained personnel; and can be used in clinical settings, pharmacies, and even at home. ${ }^{3}$ Advances in POC testing and effective deployment in-field would enable the reopening of economies, schools, and borders as well as the resumption of nearly normal operations across all fields. ${ }^{4}$

The current gold standard test for SARS-CoV-2 detection involves reverse transcription of the virus genome and quantitative polymerase chain reaction (RT-qPCR). ${ }^{5}$ RTqPCR testing requires shipping samples to a centralized facility that is equipped with thermal cyclers and staffed by highly trained personnel who extract nucleic acids and run samples. ${ }^{6}$ This approach takes several hours (or more) from sampling to result, complicating its large-scale application for recurrent community-wide testing. The detection limit of the RT-qPCR is $1 \mathrm{copy} / \mu \mathrm{L},{ }^{7}$ but because recurrent testing is necessary, test sensitivity is not necessarily a high priority. ${ }^{8}$ Recent studies indicate that a sensitivity of 100 copies $/ \mu \mathrm{L}$ suffices for efficient testing.

Received: April 24, 2021 
To overcome requirements for complex equipment, researchers have developed technologies for a single-step, isothermal amplification of nucleic acids, including loopmediated isothermal amplification (LAMP) and recombinase polymerase amplification (RPA). ${ }^{9,10}$ LAMP and RPA are costeffective, field-deployable, and scalable alternatives to PCRbased methods. ${ }^{3,11}$ Recently, RT-LAMP and RT-RPA were coupled with CRISPR Cas9, Cas12, and Cas13 enzymes for the sensitive and specific detection of nucleic acids and viruses, including SARS-CoV-2. ${ }^{12-18}$ The Cas12 and Cas13 enzymes complex with their corresponding single-guide RNA (sgRNA) and scan a DNA or RNA template for a complementary sequence. Once a complementary sequence is recognized, the enzyme cleaves the nucleic acid in cis and, once activated by the initial recognition, exhibits collateral trans cleavage activities, cleaving single-stranded (ss) DNA or RNA molecules present in the reaction. ${ }^{19,20}$ This collateral cleavage activity of Cas 12 and Cas 13 has been harnessed for nucleic acid detection. For example, the CRISPR-Cas13 system coupled with RPA is used for virus detection via SHERLOCK (Specific High-sensitivity Enzymatic Reporter unLOCKing). ${ }^{21-23}$ To bypass the need for nucleic acid purification, HUDSON (Heating Unextracted Diagnostic Samples to Obliterate Nucleases) was developed and coupled with SHERLOCK. ${ }^{24}$

The World Health Organization requires that any POC diagnostic meets the ASSURED criteria: accuracy, sensitivity, specificity, user-friendliness, rapidity, and deliverability to endusers. $^{25}$

To work toward meeting these criteria, a robust POC testing system for SARS-CoV-2 should include the following features: (1) no nucleic acid extraction, (2) fast turnaround time ( $\leq 30$ min from sample to results), (3) single-tube reactions, (4) scalability, and (5) low cost. Single-step diagnostics and singletube reactions would simplify testing and limit crosscontamination in a testing facility. Modalities that do not require amplification of the virus genome are useful for POC testing kits. Recently, Liu et al. ${ }^{26}$ and Fozouni et al. ${ }^{27}$ rapidly detected and quantified SARS-CoV-2 using CRISPR-Cas13 without the preamplification step by combining CRISPR RNAs (crRNAs) targeting different regions of the virus genome, which enhances sensitivity. This method is promising, but sophisticated signal detection devices are necessary. ${ }^{26,27}$

CRISPR/Cas systems possess great potential for various applications, so researchers continuously search for, identify, and characterize new Cas effectors to increase utility and develop new tools for in vivo and in vitro applications. ${ }^{28,29}$ Recently, substantial efforts using computational approaches for metagenomic mining resulted in the discovery of novel CRISPR/Cas systems, including class II/type VI Cas proteins that exclusively target ssRNA substrates. ${ }^{30-33}$ In addition to repurposing these RNA targeting CRISPR/Cas13s for in vivo applications, ${ }^{34-38}$ Cas13s are used in diagnostics that exhibit unprecedented sensitivity, specificity, and speed. ${ }^{20,22-24,27}$ Different Cas13 variants are used for nucleic acid detection. For example, Cas13a, ${ }^{21,39} \mathrm{Cas}^{13 b}{ }^{40}$ and Cas $13 \mathrm{~d}^{41}$ exhibit collateral cleavage activities and work for nucleic acid detection. Here, we sought to expand the Cas13-based toolbox for diagnostic applications by identifying and characterizing novel CRISPR/Cas13 effectors. In this work, we identified, characterized, and demonstrated the utility of the mCas 13 variant for SARS-CoV-2 detection. Our work illustrates the untapped potential of mCas13 enzymes in diagnostics and other in vivo RNA applications.

\section{RESULTS AND DISCUSSION}

Identification, Design, Construction, and Expression of a Novel Miniature Cas13 System. To control the pandemic of COVID-19, rapid, accurate, reliable, and portable diagnostics for SARS-CoV-2 are essential. ${ }^{1}$ However, increasing sensitivity and specificity has remained a common challenge for recently developed diagnostics. Amplification can increase the sensitivity of assays, and isothermal amplification techniques like RT-LAMP and RT-RPA are good alternatives for RT-qPCR. Both are highly sensitive, provide rapid and more accessible platforms for viral nucleic acid detection, and are suitable for POC uses. ${ }^{42-44}$ Despite many advantages of isothermal amplification in relation to other traditional amplification methods, their application is limited by the high rate of nonspecific amplification and crosscontamination. ${ }^{45,46}$ Therefore, isothermal amplification methods are coupled with CRISPR systems to enhance specificity and LoD. ${ }^{16,21,47,48}$

A recent study by $\mathrm{Xu}$ et al. $^{49}$ describes the discovery of novel compact Cas 13 effectors that are classified as CRISPR/Cas type VI-X and VI-Y. These novel compact Cas13s are used for in vivo applications, including endogenous RNA interference and RNA editing, and, interestingly, as an anti-coronavirus approach that targets and combats SARS-CoV-2 and other viruses in vivo. ${ }^{49}$

The robust and efficient activities of these novel compact Cas13s motivated us to explore the potential utility of other novel compact Cas13 effectors for diagnostic purposes. Therefore, we used some of the novel compact Cas 13 protein sequences from $\mathrm{Xu}$ et al. as queries in the Basic Local Alignment Search Tool (BLAST) to find sequences similar to potentially uncharacterized compact Cas 13 proteins. The alignment identified various proteins, including a few uncharacterized putative Cas 13 sequences with two predicted RxxxxH motifs of the conserved Cas13 Higher Eukaryotes and Prokaryotes Nucleotide-binding (HEPN) ribonuclease domains. ${ }^{32,50}$ One small ( 837 amino acids) candidate, which we named as mCas13, showed high similarity ( $>95 \%$ query coverage) to the most efficient Cas 13 identified by Xu et al., namely, Cas13X.1. ${ }^{49}$ Further analysis of the metagenomic contigs showed that the putative mCas13 protein has an associated CRISPR array in its immediate vicinity. In silico analysis of the associated CRISPR array predicted that the mCas13-associated crRNAs share high similarity with the length and architecture of the compact Cas13X.1 crRNA (a 30-nt-long spacer sequence at the $5^{\prime}$ end of the crRNA followed by a 36-nt-long direct repeat (DR) sequence at the $3^{\prime}$ end) and of previously reported crRNAs of the Cas $13 \mathrm{~b}$ family $^{35}$ (a summary sketch of the computational strategy is shown in Figure S1A). Furthermore, multiple sequence alignment analysis showed high similarity and the two predicted HEPN domains conserved among our putative mCas 13 protein, Cas13X.1, and the other compact proteins, Cas13X and Cas13Y (Figure S1B). Based on these predictions, we hypothesized that the putative mCas13 is functionally active. Next, we codon-optimized and synthesized the corresponding gene sequence and designed and constructed the mCas 13 sequence in a bacterial expression plasmid for heterologous expression in BL21 Escherichia coli. Subsequently, 
A

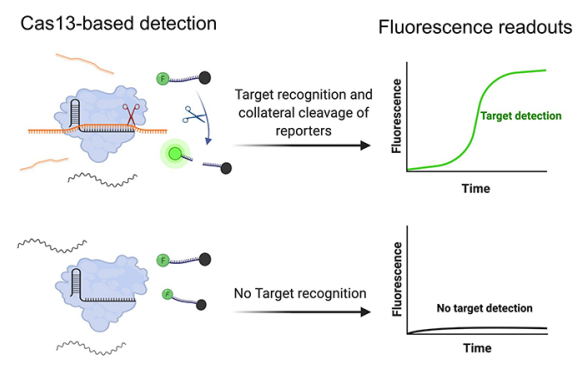

C

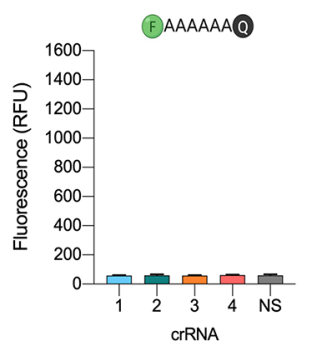

B

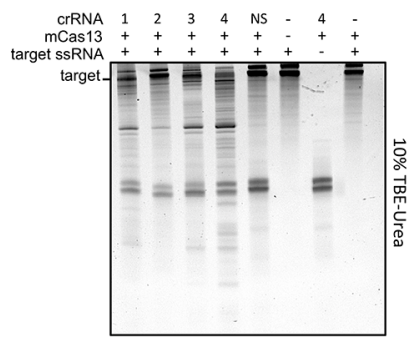

D
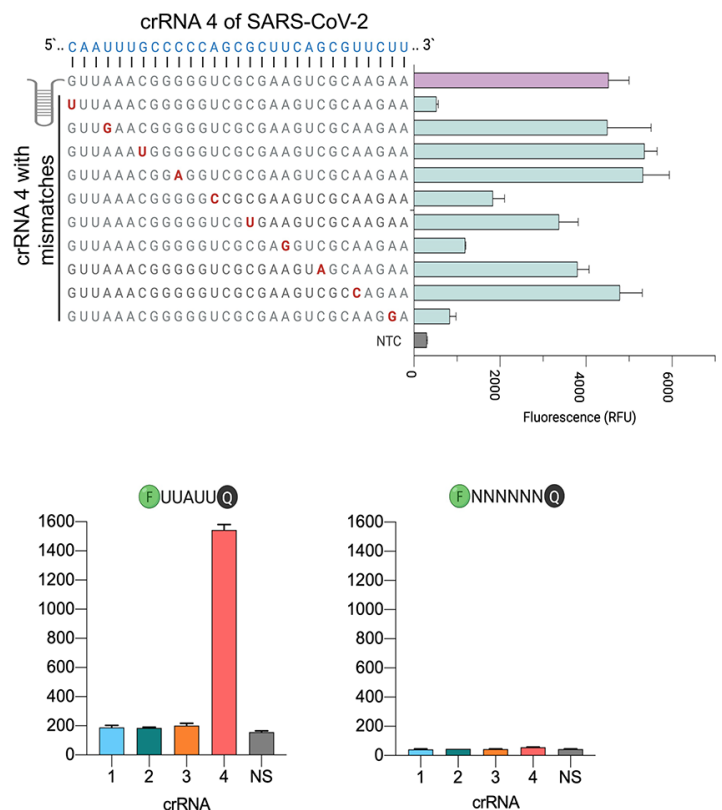

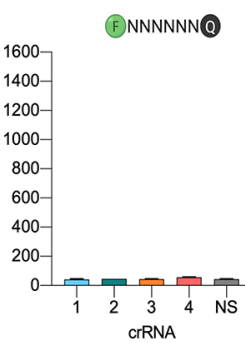

Figure 1. Characterization of mCas13-based nucleic acid detection. (A) Schematic of specific Cas13-based detection. Specific target recognition by Cas13 RNP triggers nonspecific, collateral activity that cleaves the reporters, resulting in a detectable fluorescent signal. (B) Representative denaturing gel showing the targeted in vitro RNase cleavage activity of the mCas 13 protein when incubated with the ssRNA target (404 nt) and different crRNAs. RNA cleavage activity is most evident with crRNA 4 relative to other crRNAs and nonspecific (NS) crRNA control. (C) Screening and selection of the optimal reporter and crRNA sequences. Reactions containing mCas 13 and four different crRNAs targeting the SARS-CoV-2 $N$ gene or nonspecific crRNA (NS) control were performed in the presence of one of five reporters. F-NNNNN-Q represents the RNaseAlert v2 reporter (Thermofisher). NS: nonspecific (not targeting SARS-CoV-2) crRNA. Values shown as mean \pm SD $(n=3)$. (D) Evaluating the effect of mismatches between mCas13 crRNA and target RNA on mCas13 activity. (Left) crRNA nucleotide sequence with the positions of mismatches (red) on the crRNA. (Right) The fluorescence intensity, relative to the no-template control (NTC, gray) or crRNA with no mismatches (purple), resulting from mCas13 collateral cleavage activity on each tested crRNA.

we produced the protein and tested its activity in vitro for diagnostic applications (Figure S2).

Characterization of CRISPR-mCas13 In-cis and Trans Catalytic Activities. When Cas13/crRNA ribonucleoproteins (RNP) recognize and cleave their target sequence, they also exhibit nonspecific, collateral cleavage activity that degrades ssRNAs nearby. ${ }^{50,51}$ Such collateral activity is used in nucleic acid detection applications, where a ssRNA probe (reporter) molecule provided in the Cas 13 reaction is cleaved by targetdependent Cas 13 collateral activity. ${ }^{21}$ The ssRNA reporter can contain a fluorophore linked by a short ssRNA sequence to a quencher, which emits fluorescence after the ssRNA sequence is cleaved, indicating the presence, and therefore the detection, of the target sequence (Figure 1A).

To test the mCas 13 in-cis and trans activities in vitro and to determine the most effective crRNAs to use in the mCas 13 SARS-CoV-2-based detection assays, we designed and screened 10 different crRNAs targeting two different regions in the SARS-CoV-2 nucleocapsid gene $(N)$. We first evaluated the in vitro cleavage activity of mCas 13 with four different crRNAs targeting single-stranded RNA substrates harboring target sequences complementary to the crRNA spacers. mCas13 exhibited different cleavage efficiencies with different crRNAs, with crRNA 4 mediating the highest efficiency relative to other crRNAs and controls (Figure $1 \mathrm{~B}$ and Figure S3A).

Next, because different Cas 13 proteins exhibit different cleavage preferences depending on ssRNA sequences, ${ }^{23}$ we wanted to identify the best ssRNA reporter for the mCas 13 SARS-CoV-2-based detection module. Therefore, we screened five different ssRNA probes, each conjugated to a $5^{\prime}$ fluorescent molecule (FAM) and a $3^{\prime}$ fluorescence quencher (FQ). We used the four targeting crRNAs and nonspecific (NS) crRNA used in Figure $1 \mathrm{~B}$ by incubating mCas 13 with each of the crRNAs and reporters in the presence of the synthetic ( $N$ gene) ssRNA target. Our screening consistently identified crRNA 4 with a significantly higher fluorescence signal relative to the NS crRNA control, indicating the cleavage preference of $\mathrm{mCas} 13$ for poly $(\mathrm{U})$ reporter sequences (Figure $1 \mathrm{C})$. Using the poly $(\mathrm{U})$ reporter molecule (UUAUU) to screen six more crRNAs targeting different $N$ gene region indicated that different crRNAs exhibited overall different signal levels (Figure S3B).

To find the optimal concentration of mCas 13 and crRNA for maximal detection signal, we performed the reaction with titrated mCas 13 and crRNA concentrations. We found that the optimal concentration of Cas13/crRNA RNP for a true positive signal with no significant signal in NS crRNA control was $500 \mathrm{nM}$ (Figure S3C). In addition, to determine the optimal temperature for mCas13 catalytic activity, we tested different cleavage temperature conditions ranging from 16 to $62{ }^{\circ} \mathrm{C}$. We observed maximal activity in the $20-37{ }^{\circ} \mathrm{C}$ range, which is similar to the optimal temperature of other known Cas 13 enzymes used for nucleic acid detection (Figure S3D).

Using optimized conditions and the most effective crRNA 4, we tested the effect of single mismatches between crRNA and target RNA on mCas13 RNA detection activity. We designed 10 crRNAs (based on crRNA 4) to contain a single nucleotide mismatch at different sites, with one mismatch for every three 
A

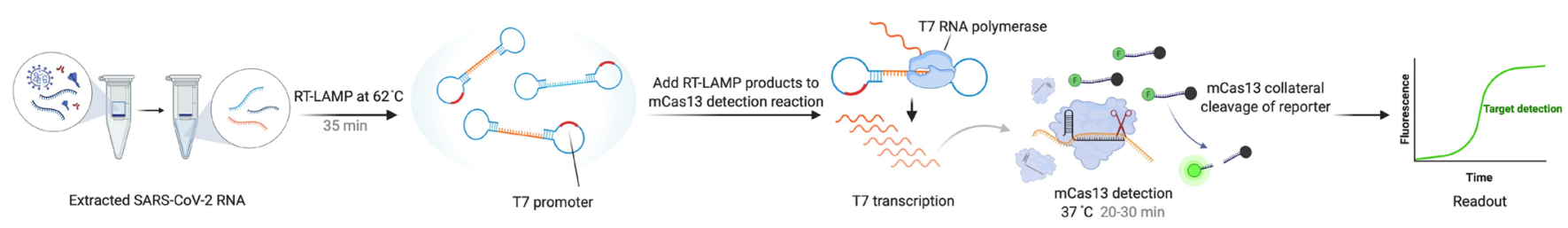

B

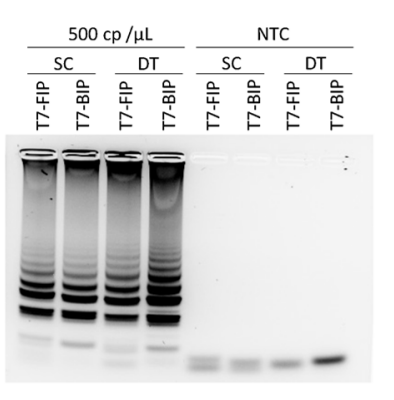

C

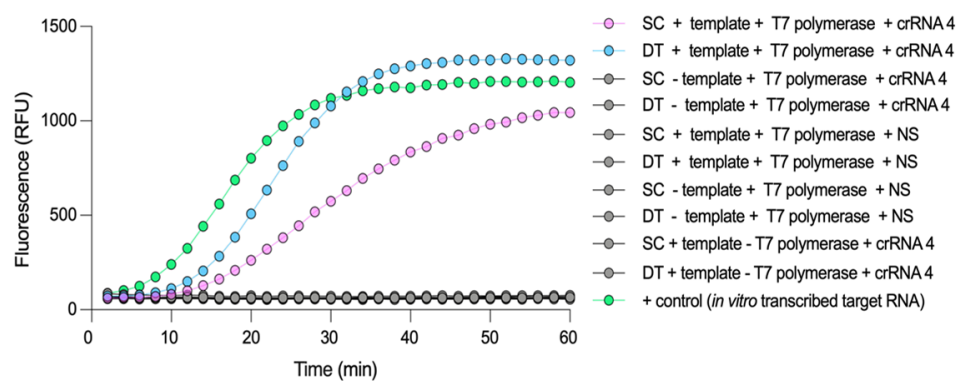

D
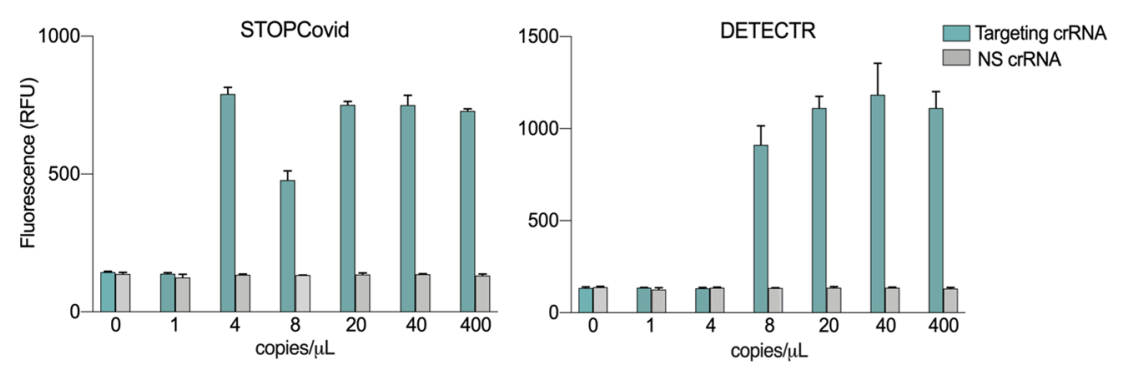

E

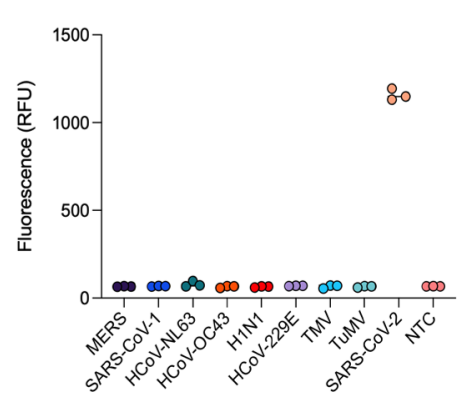

Figure 2. Detection of SARS-CoV-2 using the CRISPR-mCas13 system. (A) Schematic of assay workflow of mCas13-based detection. Following sample collection and RNA extraction, pathogen RNA is reverse transcribed and amplified via RT-LAMP isothermal reaction. RT-LAMP primer sets (in which the FIP contains a T7 promoter sequence) are used, resulting in amplicons containing the T7 promoter sequence, which serve as templates for in vitro transcription of target RNA. Upon target recognition, mCas13 cleaves specially designed reporters in trans, leading to fluorescent signal output. (B) Visualization of RT-LAMP amplicons targeting the $N$ gene, produced with FIP and BIP primers containing the T7 promoter on $2 \%$ agarose gel. NTC: no template control; SC: STOPCovid; DT: DETECTR. (C) Measurement of real-time fluorescence output of T7-mediated in vitro transcription and mCas13-based detection. Synthetic SARS-CoV-2 RNA was reverse transcribed and LAMP-amplified with STOPCovid (SC) and DETECTR (DT) primer sets. crRNA 4: targeting crRNA \#4 identified in Figure 1; NS: nonspecific crRNA. Values shown as mean $(n=3)$. (D) Limit of detection (LoD) of the mCas13-based detection assay. LoD was determined using synthetic SARS-CoV-2 RNA, which was reverse transcribed and LAMP-amplified with STOPCovid and DETECTR primer sets. The LAMP product was subsequently used for T7 in vitro transcription and concurrent mCas13 detection. Values shown as mean \pm SD $(n=3)$. (E) Specificity of the mCas13-based detection assay. Detection of nonspecific viral targets including SARS-CoV-1, MERS-CoV, H1N1, HCoV-NL63, HCoV-OC43, and HCoV-229E, as well as two plant viruses, tobacco mosaic virus (TMV) and turnip mosaic virus (TuMV), was attempted using the STOPCovid primer set $(n=3)$.

nucleotides on the spacer sequence. A low mismatch tolerance should cause a much lower detection signal than the positive control (which is a perfect match). Our analysis revealed different mismatch tolerances for different regions of the spacer sequence, where mismatches at the extreme $5^{\prime}$ or $3^{\prime}$ ends of the crRNA were not well tolerated. In contrast, mismatches at other regions were tolerated better (Figure 1D and Figure S4). The observed different tolerances for mismatches could be advantageous to designing crRNAs useful for detecting variants that harbor different SNPs. Altogether, these data indicated that the identified mCas 13 is catalytically active with a robust trans cleavage activity and thus is suitable for developing nucleic acid detection platforms.

RT-LAMP Coupled with CRISPR-mCas13 for SARSCoV-2 Detection. To ensure sensitive detection, preamplifying the RNA target of interest is necessary. ${ }^{21}$ We chose RTLAMP isothermal amplification because it possesses several advantages over other amplification methods, including high sensitivity, rapid turnaround time, simple operation, and low cost. $^{52}$ To initiate the RT-LAMP reaction, we used primer sets well-established in previous reports to target and amplify conserved regions in the SARS-CoV-2 $N$ gene, named here as STOPCovid $^{16}$ and DETECTR ${ }^{17}$ primer sets. Because mCas 13 targets RNA, we modified these primers by appending a T7 promoter sequence to the $5^{\prime}$ end of the first half of either the forward inner primer (FIP) or the backward inner primer (BIP). During LAMP amplification, the T7 promoter sequence integrates into the amplified DNA products, providing a suitable template for the T7 RNA polymerase to transcribe the amplified LAMP product in vitro and generate RNA targets for mCas13 detection (Figure 2A). We tested the performance of these modified primers using a synthetic SARS-CoV-2 viral genome at 500 copies $/ \mu \mathrm{L}$. Gel electrophoresis indicated that these modified primers successfully amplified the target RNA 


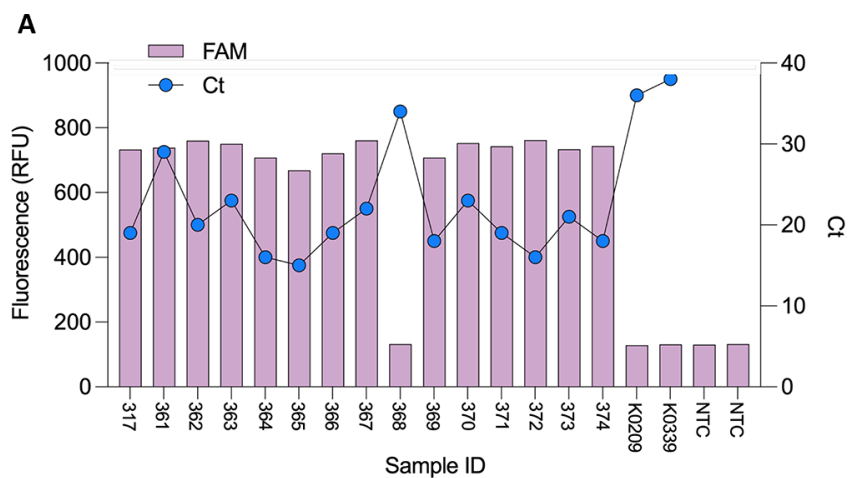

C

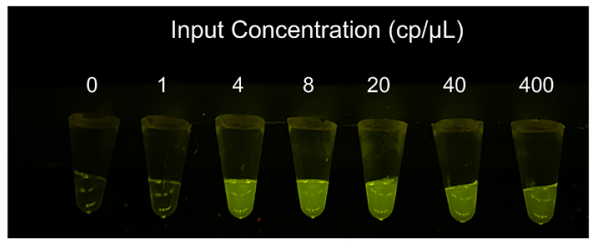

B

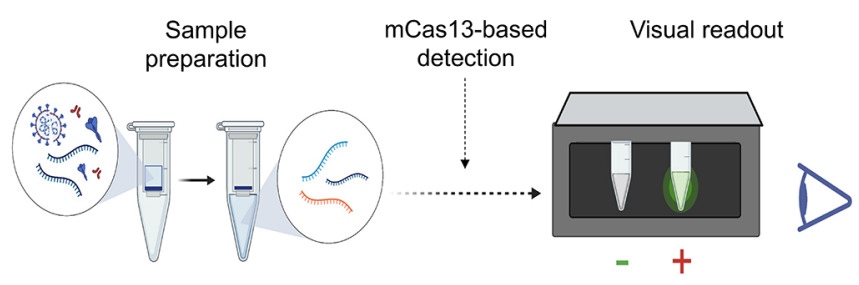

D

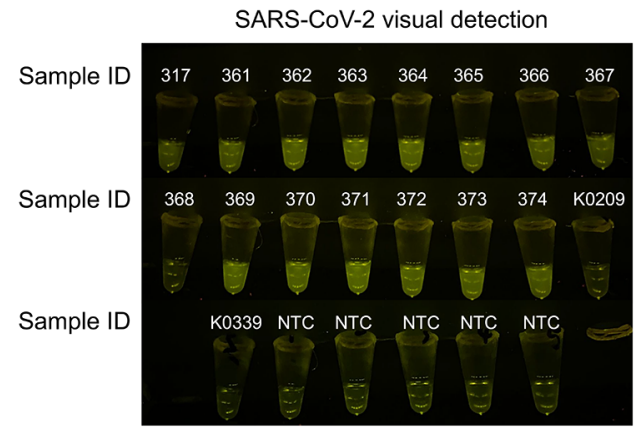

$\mathbf{E}$

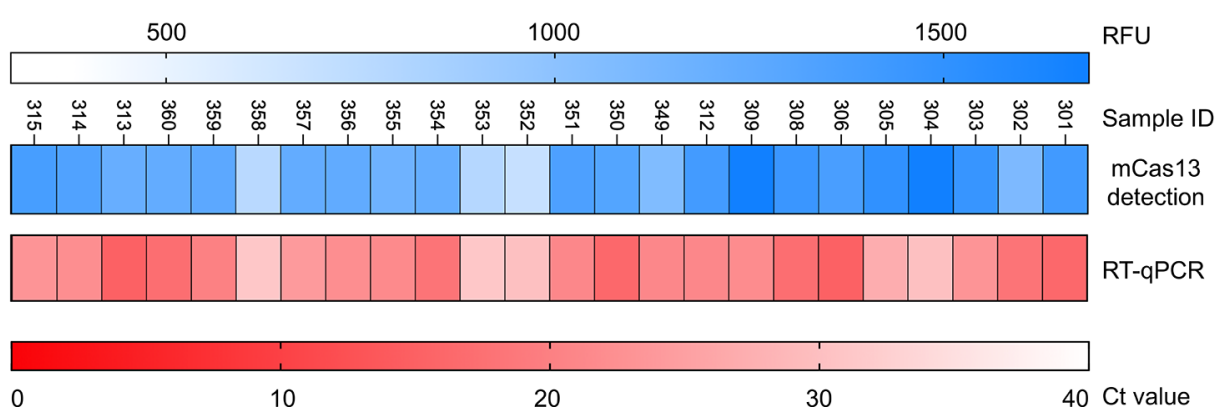

$\mathrm{F}$

\begin{tabular}{ccc} 
& $\begin{array}{c}\text { RT-qPCR } \\
+\end{array}$ & $\begin{array}{c}\text { RT-qPCR } \\
-\end{array}$ \\
\hline $\begin{array}{c}\text { mCas13 } \\
\text { detection } \\
+\end{array}$ & 38 & 0 \\
$\begin{array}{c}\text { mCas13 } \\
\text { detection } \\
-\end{array}$ & 1 & 2 \\
\hline
\end{tabular}

Figure 3. mCas13-based detection of SARS-CoV-2 in clinical samples. (A) Validation of mCas13-based detection assay on RT-qPCR-validated SARS-CoV-2 clinical samples with different Ct values. Pink bars represent the mCas13-based detection fluorescence output. FAM: RNA reporter labeled with FAM fluorophore used in mCas13 detection assays. Blue dots represent $N$ gene Ct values (Table S7). (B). Schematic representation of mCas13-based visual detection with a handheld fluorescence visualizer. (C) Limit of detection (LoD) of the mCas13-based detection assay with visual readouts. LoD was determined using synthetic SARS-CoV-2 RNA, which was reverse transcribed and LAMP-amplified with the STOPCovid primer set. The LAMP product was used for T7 in vitro transcription and concurrent mCas13 detection. (D) Validation of mCas13-based visual detection on RT-qPCR-validated SARS-CoV-2 clinical samples with different Ct values from panel (A). (E) Heat map displaying the validation of the mCas13-based visual detection assay of 24 SARS-CoV-2 RT-qPCR positive samples. RFU: random fluorescence units showing the signal intensity that was obtained by the TECAN plate reader for the mCas 13 reactions shown in Figure S6. (F) Concordance between mCas 13 detection results and RT-qPCR detection on 41 patient samples used in panels (A-E).

with no observed amplification in the no-template control (NTC) (Figure 2B). In addition, we found no substantial differences between the amplifications using primer sets with the T7-containing FIP primer (T7-FIP) or T7-containing BIP primer (T7-BIP). Therefore, we chose T7-FIP primers to establish the RT-LAMP mCas13 detection platform. These results indicate that the modification in the RT-LAMP primers did not interfere with the RT-LAMP reaction and resulted in the robust amplification of the target sequences, which allows subsequent coupling with mCas 13 for virus detection.

Since $\mathrm{mCas} 13$ showed a high activity at $37^{\circ} \mathrm{C}$ (Figure S3D), a temperature also optimal for T7 RNA polymerase, we attempted to couple the T7-mediated transcription of the RTLAMP product with the Cas13-based detection of the transcribed RNA in a single tube. Therefore, after RT-LAMP preamplification of the SARS-CoV-2 synthetic RNA using STOPCovid or DETECTR T7-FIP modified primers, we added the RT-LAMP products to the T7 transcription and mCas 13 detection reaction. Real-time measurement of the T7coupled mCas13-based detection indicated robust detection of the RT-LAMP product only when using targeting crRNA (crRNA 4 was used for all SARS-CoV-2 detection assays) and T7 RNA polymerase, confirming that the amplification of the synthetic SARS-CoV-2 genome was specific and that T7 promoters were successfully integrated into the amplified products (Figure 2C). These results indicate that we successfully created a mCas13-based two-pot SARS-CoV-2 detection platform. 
Next, we sought to determine the limit of detection (LoD) of our two-pot SARS-CoV-2 detection assay. When establishing the two-pot assay, we verified that both STOPCovid and DETECTR primer sets could be used to effectively detect SARS-CoV-2 RNA (Figure 2C). Therefore, we assayed the performance and the LoD of both STOPCovid and DETECTR primer sets to determine the primer set that is most suitable for our mCas13 SARS-CoV-2 detection platform. We used serial dilutions of the synthetic SARS-CoV-2 viral genome as an input for the preamplification RT-LAMP reaction. We found that both primer sets enable the sensitive detection of the synthetic RNA, but the STOPCovid primers reproducibly detected as few as 4 copies/ $\mu \mathrm{L}$ viral RNA compared with 8 copies/ $\mu \mathrm{L}$ for DETECTR primers (Figure 2D). Although extending the RT-LAMP amplification time could enhance its sensitivity, we limited the RT-LAMP preamplification step to $35 \mathrm{~min}$ and the mCas 13 detection reaction to $20-30 \mathrm{~min}$, limiting the total detection time to $\approx 1$ $\mathrm{h}$ or less. Due to its outstanding LoD, we chose the STOPCovid primer set for our mCas13 detection platform.

To test our assay's specificity and ensure no cross-reactivity with other common viruses, we challenged our system with other SARS-CoV-2-related or nonrelated viruses, including severe acute respiratory syndrome coronavirus 1 (SARS-CoV1), Middle East respiratory syndrome (MERS), human coronavirus NL63 (HCoV-NL63), human coronavirus OC43 (HCoV-OC43), human coronavirus 229E (HCoV-229E), H1N1 influenza, tobacco mosaic virus (TMV), and turnip mosaic virus (TuMV), together with SARS-CoV-2. All tested viruses (other than SARS-CoV-2) showed only near-background signals, indicating that the developed assay was highly specific (Figure 2E). Collectively, these results indicated that our developed mCas13-based detection platform enables reliable, highly sensitive, and highly specific detection of SARS-CoV-2 with a turnaround time of $1 \mathrm{~h}$ from extracted RNA to results.

Validation of RT-LAMP Coupled with CRISPR-mCas13 SARS-CoV-2 Detection Platform in a Clinical Setting. Next, we sought to validate our assay with total RNA extracted from SARS-CoV-2 patient swab samples. Oropharyngeal or nasopharyngeal swab samples were collected from suspected COVID-19 patients. After RNA extraction following the CDC EUA-approved protocol, we confirmed the samples positive for SARS-CoV-2 using RT-qPCR (Table S7). We first tested our assay with 17 samples with $\mathrm{Ct}$ values of 15-39. Using our mCas13-based detection assay, we correctly identified all samples with $\mathrm{Ct}$ values of less than 34 within $1 \mathrm{~h}$ (Figure 3A). These results indicated that our system can reliably detect SARS-CoV-2 in samples with Ct values up to 34 .

To enable large-scale screening during the SARS-CoV-2 pandemic, performing diagnostic assays at POC or outside of laboratory settings is critical. Therefore, we wanted to couple our assay with a portable device that enables a simple readout suitable for POC and routine diagnostics. We adapted a handheld, inexpensive fluorescence visualizer (P51 Molecular Fluorescence Viewer) to easily visualize and interpret the results. This portable device illuminates reaction tubes with blue light, and fluorescent reactions are visible through a film used as an optical filter. Using this device, fluorescence is readily visible to the human eye without the need for sophisticated instruments like qPCR machines or plate readers (Figure 3B). Using a modified RNA reporter molecule conjugated to a $5^{\prime} \mathrm{HEX}$ fluorescent molecule instead of
FAM, we found that mCas13 collateral cleavage of this reporter produced a bright signal visible with the P51 fluorescence visualizer. We optimized the HEX reporter concentration for definitive visual detection of true-positive samples and found that $1 \mu \mathrm{M}$ of HEX RNA reporters produced a clear signal with no substantial background in negative controls (Figure S5A).

Next, to ensure that the sensitivity of our assay was preserved with the change in fluorescent molecule, we repeated the LoD assay using the STOPCovid primer set. We found the same results as obtained previously with the machine-based readout in Figure 2D, demonstrating that the $5^{\prime}$ HEX modification did not affect assay performance (Figure $3 \mathrm{C}$ ). Next, we evaluated this assay's performance with the same 17 SARS-CoV-2 RNA samples used in Figure 3A. We compared the results from the visual-based detection assay to the results in Figure 3A. We found $100 \%$ concordance between the two assays, indicating that the developed mCas13 visual detection assay is reliable (Figure $3 \mathrm{D}$ and Figure S5B). Finally, to clinically validate and further test the reliability of our visual mCas13 detection assay, we tested the assay's performance with an additional 24 qPCR-confirmed positive clinical samples of total RNA extracted from patient swabs along with no-template control reactions. The visual-readout mCas13-based detection of SARS-CoV-2 from these 24 samples showed $100 \%$ concordance with RT-qPCR results. We detected a clear fluorescence signal relative to the negative controls in each positive sample (Figure 3E and Figure S6). Altogether, we validated this system's effectiveness in 41 clinical samples, enabling viral detection within $1 \mathrm{~h}$ with a simple visual readout and with good concordance with RTqPCR results (Figure $3 \mathrm{~F}$ ).

Here, we identified and characterized a novel Cas13 variant and developed an RT-LAMP coupled with mCas13 assay for SARS-CoV-2 detection. This mCas13-based detection platform enables rapid, accurate, simple, cost-effective, and efficient detection of SARS-CoV-2 and shows potential for POC applications. This work expands the toolbox and application of Cas13 enzymes in diagnostics and for potential in vivo applications.

Although efficient Cas13 variants already exist, including LwaCas13a, PspCas13b, and LbuCas13a, among others, their large size constrains their applications in vivo. However, due to its miniature size that allows the in vivo delivery via adenoassociated virus (AAV), ${ }^{53}$ the mCas 13 variant can be used for a variety of in vivo RNA manipulations, including RNA knockdown, editing, splicing regulation, RNA imaging, and localization. Intriguingly, the recently identified compact Cas13, Cas13X.1, shows efficacy against SAR-CoV-2 and influenza A virus, indicating that Cas 13 may be useful as an antiviral therapeutic. ${ }^{36}$ These studies demonstrate that bacterial defense systems have untapped potential for diverse synthetic biology applications, diagnostics, and therapeutics as antiviral agents. While this work was in progress, searching the growing number of sequenced bacterial genomes recently deposited in the NCBI database uncovered additional uncharacterized $\mathrm{mCas} 13 \mathrm{~s}$ with high sequence similarity to the mCas13 used here. We found that some of these systems have associated CRISPR arrays, with crRNA sequences and architectures similar to those of the mCas 13 crRNAs. Based on the results shown here, we anticipate that such miniature systems will prove useful for various applications, and mining 
natural resources for novel proteins with desired features is unquestionably invaluable.

In summary, we successfully identified and characterized the catalytic activities of a novel miniature variant of Cas 13 and harnessed its collateral catalytic activities to develop a system for SARS-CoV-2 detection. Our modality coupling RT-LAMP and mCas 13 demonstrates key features, including simplicity, specificity, sensitivity, and portability. We measured the readout signal using a low-cost P51 device. The P51 device can be paired with a cell phone camera that processes and shares data, facilitating the integration of this modality to largescale testing. This work illustrates the usefulness of mCas 13 systems for diagnostics as well as other potential in vivo RNA manipulations for diverse applications.

\section{MATERIALS AND METHODS}

Computational Identification of a Novel CRISPR/ mCas13. Protein sequences of novel miniature Cas $13 \mathrm{~s}$ in a recent report $^{49}$ were kindly provided by Dr. Hui Yang (Chinese Academy of Sciences, Beijing, China). These protein sequences were used as queries in the Basic Local Alignment Search Tool (BLAST) against the NCBI nonredundant (nr) protein database (before January 2021) using default settings. Only subject sequences with a query coverage (Query cover) above $90 \%$ were considered. Protein sequences of the miniature Cas13Y variants did not identify any subject sequences with a query coverage above $90 \%$. However, when using protein sequences of the miniature Cas $13 \mathrm{X}$ variants, especially Cas13X.1 (accession \#RKY08123), mCas13 (accession \#HFH51004) from Proteobacteria bacterium showed up as the only subject sequence with a query coverage above $90 \%$ (96\%).

Protein sequence alignment of $\mathrm{mCas} 13$ and the miniature Cas13X and Cas13Y variants was performed using ClustalW ${ }^{54}$ in MEGAX with default settings, and the alignment was visualized using ESPript. ${ }^{55}$ The RxxxxH HEPN motif was subsequently identified in the $\mathrm{mCas} 13$ protein sequence on the basis of this alignment and was further confirmed by manually searching for this motif using SnapGene. CRISPRCasFinder ${ }^{56}$ was performed on the genomic DNA sequence (GenBank \#DSVK01000191.1) to identify the associated CRISPR array. CRISPRDetect ${ }^{57}$ was then used to predict the orientation of the direct repeat in the mCas13 CRISPR array.

Cas 13 Protein Expression and Purification. To produce the expression plasmid for Cas 13 expression and purification, the E. coli codon-optimized Cas13 coding sequence was synthesized (GenScript) de novo and subcloned in frame with His and SUMO tags on the N-terminus into the His6TwinStrep-SUMO bacterial expression vector (Addgene \#90097) using BamHI and NotI (Tables S5 and S6). Purification of $\mathrm{mCas} 13$ protein was performed following the protocol of Kellner et al. ${ }^{22}$ with a few modifications. Briefly, the $\mathrm{mCas} 13$ expression vector was transformed into BL21 E. coli cells. Starter cultures were prepared by growing single colonies in an LB broth supplemented with $100 \mu \mathrm{g} / \mathrm{mL}$ ampicillin for $12 \mathrm{~h}$ at $37^{\circ} \mathrm{C}$. Next, $20 \mathrm{~mL}$ of the starter culture was used to inoculate $2 \mathrm{~L}$ of the Terrific Broth medium (TB) (IBI Scientific) supplemented with $100 \mu \mathrm{g} / \mathrm{mL}$ ampicillin for growth at $37^{\circ} \mathrm{C}$ until an $\mathrm{OD}_{600}$ of 0.5 . Cells were incubated on ice for $30 \mathrm{~min}$, expression was induced with $0.5 \mathrm{mM}$ IPTG, and cultures were then transferred to $16^{\circ} \mathrm{C}$ for overnight expression. Cells were harvested by centrifugation for $20 \mathrm{~min}$ at $4{ }^{\circ} \mathrm{C}$ at $4000 \mathrm{rpm}$. Cell pellets were resuspended in a lysis buffer (50 mM Tris-Cl pH 7.5, $500 \mathrm{mM} \mathrm{NaCl,} \mathrm{5 \%} \mathrm{glycerol,} 1$ mM DTT, and EDTA-free protease inhibitor (Roche)) and supplemented with $1 \mathrm{mg} / \mathrm{mL}$ lysozyme (L6876, Sigma). Cells were lysed by sonication and clarified by centrifugation at $11,000 \mathrm{rpm}$ for $50 \mathrm{~min}$. The soluble $6 x$ His-SUMO-mCas 13 in cleared lysate was then purified with an affinity chromatography column (HisTrap $\mathrm{HP}, 5 \mathrm{~mL}$ GE Healthcare) (AKTA PURE, GE Healthcare) followed by concurrent removal of the 6xHis-SUMO tag by SUMO protease and overnight dialysis in a dialysis buffer (25 mM Tris-Cl pH 7.5, $100 \mathrm{mM} \mathrm{NaCl}, 5 \%$ glycerol, and $1 \mathrm{mM}$ TCEP). Cleaved protein was concentrated to $1.5 \mathrm{~mL}$ by Amicon Ultra-15 Centrifugal Filter Units (50 kDa NMWL, UFC905024, Millipore) and further purified via size-exclusion chromatography on an S200 column (GE Healthcare $)$ in a gel filtration buffer $(50 \mathrm{mM}$ Tris $-\mathrm{HCl} \mathrm{pH}$ 7.5, $600 \mathrm{mM} \mathrm{NaCl}, 10 \%$ glycerol, and $1 \mathrm{mM}$ DTT). The protein-containing fractions resulting from the gel filtration were pooled, and the protein concentration was estimated with A280 absorbance using NanoDrop (ThermoFisher Scientific NanoDrop 8000 Spectrophotometer), snap frozen, and stored at $-80{ }^{\circ} \mathrm{C}$. The weight protein concentration was then converted into molar concentration to facilitate the calculation of final protein concentrations in reactions.

Nucleic Acid Preparation. A short region of the SARSCoV-2 $N$ gene sequence was used as a synthetic target in the preliminary $\mathrm{mCas} 13$ characterization and optimization experiments to screen crRNAs and collateral reporters and establish mCas13-based detection (Figure 1). The $N$ gene target RNA sequences were prepared by in vitro transcription of PCR amplicons containing the T7 promoter sequence using the 2019-nCoV N Positive Control plasmid as a PCR template (10006625, IDT). Purified PCR amplicons (QIAquick PCR Purification Kit, QIAGEN) were transcribed in vitro using a HiScribe T7 Quick High Yield RNA Synthesis Kit (E2050, NEB). The transcripts were purified using Direct-zol RNA Miniprep Kits (R2050, Zymo Research) following the manufacturer's instructions, and the purified RNA was stored at $-80{ }^{\circ} \mathrm{C}$.

mCas13 crRNAs were designed to target the $N$ gene sequence of the SARS-CoV-2 genome. For crRNA preparation, templates for in vitro transcription were generated using singlestranded DNA oligos containing a T7 promoter, scaffold, and spacer in reverse complement orientation (IDT) and were then annealed to a T7 forward primer in a Taq DNA polymerase buffer (Invitrogen). The annealed oligos were then used as templates for in vitro transcription as described above. NanoDrop 8000 was used to determine the concentration of the purified RNA. The weight concentration was then converted into molar concentration to facilitate the calculation of final RNA concentrations in reactions.

To establish RT-LAMP coupled with T7-mCas13-based detection and LoD range, control synthetic SARS-CoV-2 viral genomic sequences used in Figure 2 were ordered as synthetic RNA from Twist Bioscience (cat. \#102024), diluted to 10,000 RNA copies $/ \mu \mathrm{L}$, and used at indicated concentrations to create simulated clinical samples.

For the specificity assay, different synthetic viral genomes were ordered including MERS-CoV Control (cat. \#10006623, IDT), SARS-CoV Control (SARS-CoV-1) (cat. \#10006624, IDT), H1N1 (cat. \#103001, Twist Bioscience), HCoV-NL63 (cat. \#103012, Twist Bioscience), HCoV-OC43 (cat. \#103013, Twist Bioscience), and HCoV-229E (cat. \#103011, Twist Bioscience). In addition, DNA plasmids pGTMV (plasmid 
\#118755, Addgene) and TuMV clone available in our lab ${ }^{37}$ were used. All viral genomes, except TMV and TuMV, were diluted into 10,000 copies $/ \mu \mathrm{L}$ stocks and $2 \mu \mathrm{L}$ was used per reaction. For reactions with TMV and TuMV DNA plasmids, $10 \mathrm{ng} / \mu \mathrm{L}$ final concentrations were used.

For RT-LAMP amplification (described below), previously published LAMP primers designed to amplify the SARS-CoV-2 $N$ gene (Joung et al. ${ }^{16}$ and Broughton et al. ${ }^{17}$ ) were used, with modifications. The FIP or BIP primers were each designed with the appended $\mathrm{T} 7$ promoter sequence at the $5^{\prime}$ end of the first half of the primer. Such modification allows the modified primer to integrate the $\mathrm{T} 7$ promoter sequence in the LAMPamplified product for subsequent T7-mediated in vitro transcription. All oligo sequences and substrates are listed in Tables S1-S3.

In Vitro Cis Cleavage Assays. mCas 13 cleavage reactions were performed at $37{ }^{\circ} \mathrm{C}$ with synthetic, in vitro-transcribed RNA targets. Briefly, cleavage reactions were carried out in 20 $\mu \mathrm{L}$ reaction volume with $500 \mathrm{nM}$ mCas 13 protein, $500 \mathrm{nM}$ crRNAs, and $2 \mathrm{~mL}$ of $500 \mathrm{ng} / \mathrm{mL}$ target RNA in a $1 \times$ cleavage buffer (20 mM HEPES-Na pH 6.8, $50 \mathrm{mM} \mathrm{NaCl}, 5 \mathrm{mM}$ $\mathrm{MgCl}_{2}$, and $1 \mathrm{mM} \mathrm{DTT}$ ); the reactions were then incubated at $37^{\circ} \mathrm{C}$ for $1 \mathrm{~h}$. The samples were then boiled at $70{ }^{\circ} \mathrm{C}$ for $3 \mathrm{~min}$ in a $2 \times$ RNA Loading Dye (B0363S, NEB) and cooled down on ice for 3 min before loading onto a $10 \%$ polyacrylamideurea denaturing gel. Electrophoresis was conducted for $80 \mathrm{~min}$ at $25 \mathrm{~W}$. The gel was stained with the SYBR Gold Nucleic Acid Gel Stain (S11494, ThermoFisher) for $10 \mathrm{~min}$, briefly washed with a $1 \times$ Tris borate EDTA buffer, and visualized using a BioRad Molecular Imager Gel Doc system.

Screening of crRNAs and Reporters and Establishing mCas13 Collateral Detection. Activity and collateral assays of Cas 13 were performed in a $1 \times$ cleavage buffer in a $20 \mathrm{~mL}$ final reaction volume. Cas 13 and crRNAs RNPs were first assembled by mixing $500 \mathrm{nM}$ purified Cas 13 with $500 \mathrm{nM}$ crRNA (unless otherwise indicated) in the $1 \times$ cleavage buffer and $20 \mathrm{U}$ of RNaseOUT (Invitrogen) followed by incubation at $37{ }^{\circ} \mathrm{C}$ for $15 \mathrm{~min}$. Next, the assembled RNP was combined on ice with $2 \mathrm{~mL}$ of $500 \mathrm{ng} / \mathrm{mL}$ in vitro-transcribed target RNA and $250 \mathrm{nM}$ RNA reporter, and reactions were incubated for 1 $\mathrm{h}$ at $37{ }^{\circ} \mathrm{C}$ (unless otherwise indicated). Real-time or endpoint fluorescence measurements were collected on a microplate reader (M1000 PRO, TECAN) at $2 \mathrm{~min}$ intervals (for real-time measurements) using a 384-well, black/optically clear flat-bottomed plate (ThermoFisher).

RT-LAMP Reactions. Reverse transcription and isothermal amplification of target nucleic acids were performed using final concentrations of $1.6 \mathrm{mM} \mathrm{FIP/BIP}$ primers (with the T7 promoter sequence fused to either the FIP or BIP primer), 0.2 $\mathrm{mM}$ F3/B3 primers, and $0.4 \mathrm{mM} \mathrm{LF} / \mathrm{LB}$ primers; $1 \times$ Isothermal Amplification Buffer $(20 \mathrm{mM}$ Tris- $\mathrm{HCl} \mathrm{pH} 8.8$, $50 \mathrm{mM} \mathrm{KCl}, 10 \mathrm{mM}\left(\mathrm{NH}_{4}\right)_{2} \mathrm{SO}_{4}, 2 \mathrm{mM} \mathrm{MgSO}_{4}$, and $0.1 \%$ Tween 20) (B0537, NEB); $1.4 \mathrm{mM}$ dNTPs; $8 \mathrm{U}$ of Bst 2.0 WarmStart DNA Polymerase (M0538, NEB); $7.5 \mathrm{U}$ of WarmStart RTx Reverse Transcriptase (M0380, NEB); and $6 \mathrm{mM} \mathrm{MgSO}_{4}(\mathrm{~B} 1003, \mathrm{NEB})$ in $25 \mu \mathrm{L}$ reactions containing variable concentrations of SARS-CoV-2 control standards or 4 $\mathrm{mL}$ of isolated RNA from clinical samples. LAMP reactions were performed at $62{ }^{\circ} \mathrm{C}$ for $35 \mathrm{~min}$ in a PCR (C1000 Touch thermal cycler, Bio-Rad) machine.

One-Step T7 Transcription and mCas13 Detection. The two reactions, $\mathrm{T} 7$-mediated in vitro transcription and mCas13-based detection of the amplified and in vitro- transcribed target RNA, were carried out in the same tube. Briefly, $2 \mathrm{~mL}$ of the RT-LAMP reaction product was combined with the $1 \times$ cleavage buffer (described above), $500 \mathrm{nM}$ mCas $13 /$ crRNA assembled RNPs, $25 \mathrm{U}$ of T7 RNA polymerase (M0251, NEB), $1 \mathrm{mM}$ NTPs, and $250 \mathrm{nM}$ RNA reporter (UUAUU) in $20 \mathrm{~mL}$ reactions. The reactions were incubated at $37{ }^{\circ} \mathrm{C}$ for $20-30 \mathrm{~min}$.

Visual Cas13-Based Detection. For simple visualization of mCas13-based detection, RNA reporters labeled with the HEX fluorophore were used instead of the FAM fluorophore (Table S4). Collateral cleavage of HEX reporters results in a bright signal that can be easily visualized upon excitation with LED light (Ali et al. ${ }^{15}$ ). Cas13-based reactions were carried out as described above, with modifications. For each reaction, 1 $\mathrm{mM}$ of the HEX reporter (unless otherwise indicated) was used in $20 \mathrm{~mL} \mathrm{T7-mCas} 13$ detection reactions. Reactions were incubated at $37{ }^{\circ} \mathrm{C}$ for $30 \mathrm{~min}$. Reaction tubes were then transferred into the P51 Molecular Fluorescence Viewer (miniPCR), and photos were taken using a smartphone with default settings.

Clinical Sample Collection and RNA Extraction. Oropharyngeal and nasopharyngeal swabs were collected from suspected COVID-19 patients by physicians in Ministry of Health hospitals in Saudi Arabia and placed in $2 \mathrm{~mL}$ screwcapped cryotubes containing $1 \mathrm{~mL}$ of TRIZOL for inactivation and transport. Each sample tube was sprayed with $70 \%$ ethanol, enveloped with absorbent tissues, and then placed and sealed in individually labeled biohazard bags. The bags were then placed in leak-proof boxes and sprayed with $70 \%$ ethanol before placement in a dry ice container for transfer to the King Abdullah University of Science and Technology (KAUST). Total RNA was extracted from the samples following instructions as described in the CDC EUA-approved protocol and using the Direct-zol kit (Direct-zol RNA Miniprep, Zymo Research; catalog \#R2070) following the manufacturer's instructions.

Real-Time Reverse Transcription PCR (RT-PCR) for Detecting Positive SARS-CoV-2 RNA Samples. RT-PCR was conducted on extracted RNA samples using the oligonucleotide primer/probe (Integrated DNA Technologies, catalog \#10006606) and Superscript III one-step RT-PCR system with Platinum Taq Polymerase (catalog \#12574-026) following the manufacturer's protocol.

\section{ASSOCIATED CONTENT}

\section{SI Supporting Information}

The Supporting Information is available free of charge at https://pubs.acs.org/doi/10.1021/acssynbio.1c00181.

Computational pipeline for the identification of the RNA-targeting mCas 13 protein, protein purification of $\mathrm{mCas} 13$, evaluation of $\mathrm{mCas} 13$ activity, characterization of mCas13 sensitivity to single mismatch between crRNA and the target sequence, visual detection of SARS-CoV-2 RNA with RT-LAMP mCas13, and validation of $\mathrm{mCas} 13$-based visual detection with SARS-CoV-2 clinical samples (Figures S1-S8); crRNA sequences used in this study, RT-LAMP primers used in this study, primers to PCR amplify $\mathrm{N}$ gene regions for IVT, RNA reporter designs and sequences used in this study, mCas13 DNA sequence and tag sequences for protein purification, mCas 13 protein sequence and tag sequences for protein purification, clinical sample 
information, and properties of different CRISPR-based assays for SARS-CoV-2 detection (Tables S1-S8) (PDF)

\section{AUTHOR INFORMATION}

\section{Corresponding Author}

Magdy M. Mahfouz - Laboratory for Genome Engineering and Synthetic Biology, Division of Biological Sciences, 4700 King Abdullah University of Science and Technology, Thuwal 23955-6900, Saudi Arabia; (1) orcid.org/0000-0002-06166365; Email: magdy.mahfouz@kaust.edu.sa

\section{Authors \\ Ahmed Mahas - Laboratory for Genome Engineering and Synthetic Biology, Division of Biological Sciences, 4700 King Abdullah University of Science and Technology, Thuwal 23955-6900, Saudi Arabia \\ Qiaochu Wang - Laboratory for Genome Engineering and Synthetic Biology, Division of Biological Sciences, 4700 King Abdullah University of Science and Technology, Thuwal 23955-6900, Saudi Arabia \\ Tin Marsic - Laboratory for Genome Engineering and Synthetic Biology, Division of Biological Sciences, 4700 King Abdullah University of Science and Technology, Thuwal 23955-6900, Saudi Arabia}

Complete contact information is available at:

https://pubs.acs.org/10.1021/acssynbio.1c00181

\section{Author Contributions}

M.M. conceived the research. A.M. identified the mCas13 variants and designed the research. A.M., Q.W., and T.M. performed the research. A.M. and M.M. wrote the paper with input from all authors.

\section{Notes}

The authors declare the following competing financial interest(s): A patent application has been filed based on this work.

\section{ACKNOWLEDGMENTS}

We would like to thank Mr. Mohammad Alarawi for providing the RNA of SARS-CoV-2 clinical samples. We also thank members of the genome engineering and synthetic biology laboratory for insightful discussions and technical support. We would like to thank Chunlong $\mathrm{Xu}$ and Hui Yang, Chinese Academy of Sciences, for sharing the sequence of their miniature Cas13 enzymes. This work was supported, in part, by the Smart Health Initiative at KAUST and the IAF grant from the KAUST IED to M.M. and by the King Abdulaziz City for Science and Technology (KACST) (RGC/3/4428-01-01).

\section{REFERENCES}

(1) Kelly-Cirino, C. D.; Nkengasong, J.; Kettler, H.; Tongio, I.; GayAndrieu, F.; Escadafal, C.; Piot, P.; Peeling, R. W.; Gadde, R.; Boehme, C. Importance of diagnostics in epidemic and pandemic preparedness. BMJ Global Health 2019, 4, No. e001179.

(2) McDermott, J. H.; Burn, J.; Donnai, D.; Newman, W. G. The rise of point-of-care genetics: how the SARS-CoV-2 pandemic will accelerate adoption of genetic testing in the acute setting. Eur. J. Hum. Genet. 2021, 29, 891-893.

(3) Esbin, M. N.; Whitney, O. N.; Chong, S.; Maurer, A.; Darzacq, $\mathrm{X}$.; Tjian, R. Overcoming the bottleneck to widespread testing: a rapid review of nucleic acid testing approaches for COVID-19 detection. RNA 2020, 26, 771-783.
(4) Niemz, A.; Ferguson, T. M.; Boyle, D. S. Point-of-care nucleic acid testing for infectious diseases. Trends Biotechnol. 2011, 29, 240250.

(5) Corman, V. M.; Landt, O.; Kaiser, M.; Molenkamp, R.; Meijer, A.; Chu, D. K.; Bleicker, T.; Brunink, S.; Schneider, J.; Schmidt, M. L.; Mulders, D. G.; Haagmans, B. L.; van der Veer, B.; van den Brink, S.; Wijsman, L.; Goderski, G.; Romette, J. L.; Ellis, J.; Zambon, M.; Peiris, M.; Goossens, H.; Reusken, C.; Koopmans, M. P.; Drosten, C. Detection of 2019 novel coronavirus $(2019-\mathrm{nCoV})$ by real-time RTPCR. Eurosurveillance 2020, 25, DOI: 10.2807/15607917.ES.2020.25.3.2000045.

(6) Morshed, M. G.; Lee, M. K.; Jorgensen, D.; Isaac-Renton, J. L. Molecular methods used in clinical laboratory: prospects and pitfalls. FEMS Immunol. Med. Microbiol. 2007, 49, 184-191.

(7) Vogels, C. B. F.; Brito, A. F.; Wyllie, A. L.; Fauver, J. R.; Ott, I. M.; Kalinich, C. C.; Petrone, M. E.; Casanovas-Massana, A.; Catherine Muenker, M.; Moore, A. J.; Klein, J.; Lu, P.; Lu-Culligan, A.; Jiang, X.; Kim, D. J.; Kudo, E.; Mao, T.; Moriyama, M.; Oh, J. E.; Park, A.; Silva, J.; Song, E.; Takahashi, T.; Taura, M.; Tokuyama, M.; Venkataraman, A.; Weizman, O. E.; Wong, P.; Yang, Y.; Cheemarla, N. R.; White, E. B.; Lapidus, S.; Earnest, R.; Geng, B.; Vijayakumar, P.; Odio, C.; Fournier, J.; Bermejo, S.; Farhadian, S.; Dela Cruz, C. S.; Iwasaki, A.; Ko, A. I.; Landry, M. L.; Foxman, E. F.; Grubaugh, N. D. Analytical sensitivity and efficiency comparisons of SARS-CoV-2 RTqPCR primer-probe sets. Nat Microbiol 2020, 5, 1299-1305.

(8) Larremore, D. B.; Wilder, B.; Lester, E.; Shehata, S.; Burke, J. M.; Hay, J. A.; Milind, T.; Mina, M. J.; Parker, R. Test sensitivity is secondary to frequency and turnaround time for COVID-19 surveillance. medRxiv; 2020.

(9) Piepenburg, O.; Williams, C. H.; Stemple, D. L.; Armes, N. A. DNA detection using recombination proteins. PLoS Biol. 2006, 4, No. e204.

(10) Notomi, T.; Okayama, H.; Masubuchi, H.; Yonekawa, T.; Watanabe, K.; Amino, N.; Hase, T. Loop-mediated isothermal amplification of DNA. Nucleic Acids Res. 2000, 28, 63e.

(11) Obande, G. A.; Banga Singh, K. K. Current and Future Perspectives on Isothermal Nucleic Acid Amplification Technologies for Diagnosing Infections. Infect Drug Resist 2020, Volume 13, 455483.

(12) Ning, B.; Yu, T.; Zhang, S.; Huang, Z.; Tian, D.; Lin, Z.; Niu, A.; Golden, N.; Hensley, K.; Threeton, B.; Lyon, C. J.; Yin, X.-M.; Roy, C. J.; Saba, N. S.; Rappaport, J.; Wei, Q.; Hu, T. Y. A smartphone-read ultrasensitive and quantitative saliva test for COVID-19. Sci. Adv. 2021, 7, eabe3703.

(13) Patchsung, M.; Jantarug, K.; Pattama, A.; Aphicho, K.; Suraritdechachai, S.; Meesawat, P.; Sappakhaw, K.; Leelahakorn, N.; Ruenkam, T.; Wongsatit, T.; Athipanyasilp, N.; Eiamthong, B.; Lakkanasirorat, B.; Phoodokmai, T.; Niljianskul, N.; Pakotiprapha, D.; Chanarat, S.; Homchan, A.; Tinikul, R.; Kamutira, P.; Phiwkaow, K.; Soithongcharoen, S.; Kantiwiriyawanitch, C.; Pongsupasa, V.; Trisrivirat, D.; Jaroensuk, J.; Wongnate, T.; Maenpuen, S.; Chaiyen, P.; Kamnerdnakta, S.; Swangsri, J.; Chuthapisith, S.; Sirivatanauksorn, Y.; Chaimayo, C.; Sutthent, R.; Kantakamalakul, W.; Joung, J.; Ladha, A.; Jin, X.; Gootenberg, J. S.; Abudayyeh, O. O.; Zhang, F.; Horthongkham, N.; Uttamapinant, C. Clinical validation of a Cas13-based assay for the detection of SARS-CoV-2 RNA. Nat. Biomed. Eng. 2020, 4, 1140-1149.

(14) Arizti-Sanz, J.; Freije, C. A.; Stanton, A. C.; Petros, B. A.; Boehm, C. K.; Siddiqui, S.; Shaw, B. M.; Adams, G.; KosokoThoroddsen, T.-S. F.; Kemball, M. E.; Uwanibe, J. N.; Ajogbasile, F. V.; Eromon, P. E.; Gross, R.; Wronka, L.; Caviness, K.; Hensley, L. E.; Bergman, N. H.; MacInnis, B. L.; Happi, C. T.; Lemieux, J. E.; Sabeti, P. C.; Myhrvold, C. Streamlined inactivation, amplification, and Cas13-based detection of SARS-CoV-2. Nat. Commun. 2020, 11, 5921.

(15) Ali, Z.; Aman, R.; Mahas, A.; Rao, G. S.; Tehseen, M.; Marsic, T.; Salunke, R.; Subudhi, A. K.; Hala, S. M.; Hamdan, S. M.; Pain, A.; Alofi, F. S.; Alsomali, A.; Hashem, A. M.; Khogeer, A.; Almontashiri, N. A. M.; Abedalthagafi, M.; Hassan, N.; Mahfouz, M. M. iSCAN: An 
RT-LAMP-coupled CRISPR-Cas12 module for rapid, sensitive detection of SARS-CoV-2. Virus Res. 2020, 288, 198129.

(16) Joung, J.; Ladha, A.; Saito, M.; Kim, N. G.; Woolley, A. E.; Segel, M.; Barretto, R. P. J.; Ranu, A.; Macrae, R. K.; Faure, G.; Ioannidi, E. I.; Krajeski, R. N.; Bruneau, R.; Huang, M.-. L. W.; Yu, X. G.; Li, J. Z.; Walker, B. D.; Hung, D. T.; Greninger, A. L.; Jerome, K. R.; Gootenberg, J. S.; Abudayyeh, O. O.; Zhang, F. Detection of SARS-CoV-2 with SHERLOCK One-Pot Testing. N. Engl. J. Med. 2020, 383, 1492-1494.

(17) Broughton, J. P.; Deng, X.; Yu, G.; Fasching, C. L.; Servellita, V.; Singh, J.; Miao, X.; Streithorst, J. A.; Granados, A.; SotomayorGonzalez, A.; Zorn, K.; Gopez, A.; Hsu, E.; Gu, W.; Miller, S.; Pan, C. Y.; Guevara, H.; Wadford, D. A.; Chen, J. S.; Chiu, C. Y. CRISPRCas12-based detection of SARS-CoV-2. Nat. Biotechnol. 2020, 38, 870-874.

(18) Marsic, T.; Ali, Z.; Tehseen, M.; Mahas, A.; Hamdan, S.; Mahfouz, M. Vigilant: An Engineered VirD2-Cas9 Complex for Lateral Flow Assay-Based Detection of SARS-CoV2. Nano Lett. 2021, 21, 3596-3603.

(19) Aman, R.; Mahas, A.; Mahfouz, M. Nucleic Acid Detection Using CRISPR/Cas Biosensing Technologies. ACS Synth. Biol. 2020, 9, $1226-1233$.

(20) Li, Y.; Li, S.; Wang, J.; Liu, G. CRISPR/Cas Systems towards Next-Generation Biosensing. Trends Biotechnol. 2019, 37, 730-743.

(21) Gootenberg, J. S.; Abudayyeh, O. O.; Lee, J. W.; Essletzbichler, P.; Dy, A. J.; Joung, J.; Verdine, V.; Donghia, N.; Daringer, N. M.; Freije, C. A.; Myhrvold, C.; Bhattacharyya, R. P.; Livny, J.; Regev, A.; Koonin, E. V.; Hung, D. T.; Sabeti, P. C.; Collins, J. J.; Zhang, F. Nucleic acid detection with CRISPR-Cas13a/C2c2. Science 2017, $356,438-442$.

(22) Kellner, M. J.; Koob, J. G.; Gootenberg, J. S.; Abudayyeh, O. O.; Zhang, F. SHERLOCK: nucleic acid detection with CRISPR nucleases. Nat. Protoc. 2019, 14, 2986-3012.

(23) Gootenberg, J. S.; Abudayyeh, O. O.; Kellner, M. J.; Joung, J.; Collins, J. J.; Zhang, F. Multiplexed and portable nucleic acid detection platform with Cas13, Cas12a, and Csm6. Science 2018, 360, 439-444.

(24) Myhrvold, C.; Freije, C. A.; Gootenberg, J. S.; Abudayyeh, O. O.; Metsky, H. C.; Durbin, A. F.; Kellner, M. J.; Tan, A. L.; Paul, L. M.; Parham, L. A.; Garcia, K. F.; Barnes, K. G.; Chak, B.; Mondini, A.; Nogueira, M. L.; Isern, S.; Michael, S. F.; Lorenzana, I.; Yozwiak, N. L.; MacInnis, B. L.; Bosch, I.; Gehrke, L.; Zhang, F.; Sabeti, P. C. Field-deployable viral diagnostics using CRISPR-Cas13. Science 2018, 360, 444-448.

(25) Mabey, D.; Peeling, R. W.; Ustianowski, A.; Perkins, M. D. Diagnostics for the developing world. Nat Rev Microbiol 2004, 2, 231-240.

(26) Liu, T. Y., Knott, G. J., Smock, D. C. J., Desmarais, J. J., Son, S., Bhuiya, A., Jakhanwal, S., Prywes, N., Agrawal, S., de Leon Derby, M. D., Switz, N. A., Armstrong, M., Harris, A. R., Charles, E. J., Thornton, B. W., Fozouni, P., Shu, J., Stephens, S. I., Kumar, G. R., Zhao, C., Mok, A., Iavarone, A. T., Escajeda, A. M., McIntosh, R., Kim, S. E., Dugan, E. J., Consortium, I. G. I. T., Pollard, K. S., Tan, M. X., Ott, M., Fletcher, D. A., Lareau, L. F., Hsu, P. D., Savage, D. F., Doudna, J. A. (2021) Accelerated RNA detection using tandem CRISPR nucleases, medRxiv.

(27) Fozouni, P.; Son, S.; Diaz de Leon Derby, M.; Knott, G. J.; Gray, C. N.; D’Ambrosio, M. V.; Zhao, C.; Switz, N. A.; Kumar, G. R.; Stephens, S. I.; Boehm, D.; Tsou, C. L.; Shu, J.; Bhuiya, A.; Armstrong, M.; Harris, A. R.; Chen, P. Y.; Osterloh, J. M.; MeyerFranke, A.; Joehnk, B.; Walcott, K.; Sil, A.; Langelier, C.; Pollard, K. S.; Crawford, E. D.; Puschnik, A. S.; Phelps, M.; Kistler, A.; DeRisi, J. L.; Doudna, J. A.; Fletcher, D. A.; Ott, M. Amplification-free detection of SARS-CoV-2 with CRISPR-Cas13a and mobile phone microscopy. Cell 2021, 184, No. e329.

(28) Burstein, D.; Harrington, L. B.; Strutt, S. C.; Probst, A. J.; Anantharaman, K.; Thomas, B. C.; Doudna, J. A.; Banfield, J. F. New CRISPR-Cas systems from uncultivated microbes. Nature 2017, 542, 237-241.
(29) Al-Shayeb, B.; Sachdeva, R.; Chen, L. X.; Ward, F.; Munk, P.; Devoto, A.; Castelle, C. J.; Olm, M. R.; Bouma-Gregson, K.; Amano, Y.; He, C.; Meheust, R.; Brooks, B.; Thomas, A.; Lavy, A.; MatheusCarnevali, P.; Sun, C.; Goltsman, D. S. A.; Borton, M. A.; Sharrar, A.; Jaffe, A. L.; Nelson, T. C.; Kantor, R.; Keren, R.; Lane, K. R.; Farag, I. F.; Lei, S.; Finstad, K.; Amundson, R.; Anantharaman, K.; Zhou, J.; Probst, A. J.; Power, M. E.; Tringe, S. G.; Li, W. J.; Wrighton, K.; Harrison, S.; Morowitz, M.; Relman, D. A.; Doudna, J. A.; Lehours, A. C.; Warren, L.; Cate, J. H. D.; Santini, J. M.; Banfield, J. F. Clades of huge phages from across Earth's ecosystems. Nature 2020, 578, 425431.

(30) Smargon, A. A.; Cox, D. B. T.; Pyzocha, N. K.; Zheng, K.; Slaymaker, I. M.; Gootenberg, J. S.; Abudayyeh, O. A.; Essletzbichler, P.; Shmakov, S.; Makarova, K. S.; Koonin, E. V.; Zhang, F. Cas13b Is a Type VI-B CRISPR-Associated RNA-Guided RNase Differentially Regulated by Accessory Proteins Csx27 and Csx28. Mol. Cell 2017, 65, No. e617.

(31) Yan, W. X.; Chong, S.; Zhang, H.; Makarova, K. S.; Koonin, E. V.; Cheng, D. R.; Scott, D. A. Cas13d Is a Compact RNA-Targeting Type VI CRISPR Effector Positively Modulated by a WYL-DomainContaining Accessory Protein. Mol. Cell 2018, 70, 327.

(32) Shmakov, S.; Abudayyeh, O. O.; Makarova, K. S.; Wolf, Y. I.; Gootenberg, J. S.; Semenova, E.; Minakhin, L.; Joung, J.; Konermann, S.; Severinov, K.; Zhang, F.; Koonin, E. V. Discovery and Functional Characterization of Diverse Class 2 CRISPR-Cas Systems. Mol. Cell 2015, 60, 385-397.

(33) Konermann, S.; Lotfy, P.; Brideau, N. J.; Oki, J.; Shokhirev, M. N.; Hsu, P. D. Transcriptome Engineering with RNA-Targeting Type VI-D CRISPR Effectors. Cell 2018, 173, 665.

(34) Abudayyeh, O. O.; Gootenberg, J. S.; Essletzbichler, P.; Han, S.; Joung, J.; Belanto, J. J.; Verdine, V.; Cox, D. B. T.; Kellner, M. J.; Regev, A.; Lander, E. S.; Voytas, D. F.; Ting, A. Y.; Zhang, F. RNA targeting with CRISPR-Cas13. Nature 2017, 550, 280-284.

(35) Cox, D. B. T.; Gootenberg, J. S.; Abudayyeh, O. O.; Franklin, B.; Kellner, M. J.; Joung, J.; Zhang, F. RNA editing with CRISPRCas13. Science 2017, 358, 1019-1027.

(36) Abbott, T. R.; Dhamdhere, G.; Liu, Y.; Lin, X.; Goudy, L.; Zeng, L.; Chemparathy, A.; Chmura, S.; Heaton, N. S.; Debs, R.; Pande, T.; Endy, D.; La Russa, M. F.; Lewis, D. B.; Qi, L. S. Development of CRISPR as an Antiviral Strategy to Combat SARSCoV-2 and Influenza. Cell 2020, 181, 865.

(37) Mahas, A.; Aman, R.; Mahfouz, M. CRISPR-Cas13d mediates robust RNA virus interference in plants. Genome Biol. 2019, 20, 263.

(38) Aman, R.; Ali, Z.; Butt, H.; Mahas, A.; Aljedaani, F.; Khan, M. Z.; Ding, S.; Mahfouz, M. RNA virus interference via CRISPR/ Cas13a system in plants. Genome Biol. 2018, 19, 1.

(39) Ackerman, C. M.; Myhrvold, C.; Thakku, S. G.; Freije, C. A.; Metsky, H. C.; Yang, D. K.; Ye, S. H.; Boehm, C. K.; KosokoThoroddsen, T.-S. F.; Kehe, J.; Nguyen, T. G.; Carter, A.; Kulesa, A.; Barnes, J. R.; Dugan, V. G.; Hung, D. T.; Blainey, P. C.; Sabeti, P. C. Massively multiplexed nucleic acid detection with Cas13. Nature 2020, 582, 277-282.

(40) Freije, C. A.; Myhrvold, C.; Boehm, C. K.; Lin, A. E.; Welch, N. L.; Carter, A.; Metsky, H. C.; Luo, C. Y.; Abudayyeh, O. O.; Gootenberg, J. S.; Yozwiak, N. L.; Zhang, F.; Sabeti, P. C. Programmable Inhibition and Detection of RNA Viruses Using Cas13. Mol. Cell 2019, 76, 826.

(41) Brogan, D. J.; Chaverra-Rodriguez, D.; Lin, C. P.; Smidler, A. L.; Yang, T.; Alcantara, L. M.; Antoshechkin, I.; Liu, J.; Raban, R. R.; Belda-Ferre, P.; Knight, R.; Komives, E. A.; Akbari, O. S. A Sensitive, Rapid, and Portable CasRx-based Diagnostic Assay for SARS-CoV-2. medRxiv; 2020.

(42) Dao Thi, V. L.; Herbst, K.; Boerner, K.; Meurer, M.; Kremer, L. P.; Kirrmaier, D.; Freistaedter, A.; Papagiannidis, D.; Galmozzi, C.; Stanifer, M. L.; Boulant, S.; Klein, S.; Chlanda, P.; Khalid, D.; Barreto Miranda, I.; Schnitzler, P.; Kräusslich, H.-G.; Knop, M.; Anders, S. A colorimetric RT-LAMP assay and LAMP-sequencing for detecting SARS-CoV-2 RNA in clinical samples. Sci. Transl. Med. 2020, 12, eabc7075. 
(43) Ganguli, A.; Mostafa, A.; Berger, J.; Aydin, M.; Sun, F.; Valera, E.; Cunningham, B. T.; King, W. P.; Bashir, R. Rapid Isothermal Amplification and Portable Detection System for SARS-CoV-2. bioRxiv;. 2020.

(44) Qian, J.; Boswell, S. A.; Chidley, C.; Lu, Z. X.; Pettit, M. E.; Gaudio, B. L.; Fajnzylber, J. M.; Ingram, R. T.; Ward, R. H.; Li, J. Z.; Springer, M. An enhanced isothermal amplification assay for viral detection. bioRxiv; 2020.

(45) Nagai, K.; Horita, N.; Yamamoto, M.; Tsukahara, T.; Nagakura, H.; Tashiro, K.; Shibata, Y.; Watanabe, H.; Nakashima, K.; Ushio, R.; Ikeda, M.; Narita, A.; Kanai, A.; Sato, T.; Kaneko, T. Diagnostic test accuracy of loop-mediated isothermal amplification assay for Mycobacterium tuberculosis: systematic review and meta-analysis. Sci. Rep. 2016, 6, 39090.

(46) Chou, P. H.; Lin, Y. C.; Teng, P. H.; Chen, C. L.; Lee, P. Y. Real-time target-specific detection of loop-mediated isothermal amplification for white spot syndrome virus using fluorescence energy transfer-based probes. J. Virol. Methods 2011, 173, 67-74.

(47) Aman, R.; Mahas, A.; Marsic, T.; Hassan, N.; Mahfouz, M. M. Efficient, Rapid, and Sensitive Detection of Plant RNA Viruses With One-Pot RT-RPA-CRISPR/Cas12a Assay. Front Microbiol 2020, 11, 610872.

(48) Mahas, A.; Hassan, N.; Aman, R.; Marsic, T.; Wang, Q.; Ali, Z.; Mahfouz, M. M. LAMP-Coupled CRISPR-Cas12a Module for Rapid and Sensitive Detection of Plant DNA Viruses. Viruses 2021, 13, 466.

(49) Xu, C.; Zhou, Y.; Xiao, Q.; He, B.; Geng, G.; Wang, Z.; Cao, B.; Dong, X.; Bai, W.; Wang, Y.; Wang, X.; Zhou, D.; Yuan, T.; Huo, X.; Lai, J.; Yang, H. Programmable RNA editing with compact CRISPRCas13 systems from uncultivated microbes. Nat. Methods 2021, 18, 499-506.

(50) Abudayyeh, O. O.; Gootenberg, J. S.; Konermann, S.; Joung, J.; Slaymaker, I. M.; Cox, D. B. T.; Shmakov, S.; Makarova, K. S.; Semenova, E.; Minakhin, L.; Severinov, K.; Regev, A.; Lander, E. S.; Koonin, E. V.; Zhang, F. C2c2 is a single-component programmable RNA-guided RNA-targeting CRISPR effector. Science 2016, 353, aaf5573.

(51) East-Seletsky, A.; O’Connell, M. R.; Knight, S. C.; Burstein, D.; Cate, J. H.; Tjian, R.; Doudna, J. A. Two distinct RNase activities of CRISPR-C2c2 enable guide-RNA processing and RNA detection. Nature 2016, 538, 270-273.

(52) Thompson, D.; Lei, Y. Mini review: Recent progress in RTLAMP enabled COVID-19 detection. Sens. Actuators Rep. 2020, 2, 100017.

(53) Wang, D.; Zhang, F.; Gao, G. CRISPR-Based Therapeutic Genome Editing: Strategies and In Vivo Delivery by AAV Vectors. Cell 2020, 181, 136-150.

(54) Larkin, M. A.; Blackshields, G.; Brown, N. P.; Chenna, R.; McGettigan, P. A.; McWilliam, H.; Valentin, F.; Wallace, I. M.; Wilm, A.; Lopez, R.; Thompson, J. D.; Gibson, T. J.; Higgins, D. G. Clustal W and Clustal X version 2.0. Bioinformatics 2007, 23, 2947-2948.

(55) Gouet, P.; Courcelle, E.; Stuart, D. I.; Metoz, F. ESPript: analysis of multiple sequence alignments in PostScript. Bioinformatics 1999, 15, 305-308.

(56) Couvin, D.; Bernheim, A.; Toffano-Nioche, C.; Touchon, M.; Michalik, J.; Néron, B.; Rocha, E. P. C.; Vergnaud, G.; Gautheret, D.; Pourcel, C. CRISPRCasFinder, an update of CRISRFinder, includes a portable version, enhanced performance and integrates search for Cas proteins. Nucleic Acids Res. 2018, 46, W246-W251.

(57) Biswas, A.; Staals, R. H.; Morales, S. E.; Fineran, P. C.; Brown, C. M. CRISPRDetect: A flexible algorithm to define CRISPR arrays. BMC Genomics 2016, 17, 356. 